\title{
O DIAGNÓSTICO DA LINGUAGEM E A LINGUAGEM DO DIAGNÓSTICO: UMA PERSPECTIVA PRAGMÁTICA
}

THE DIAGNOSIS OF LANGUAGE AND THE LANGUAGE OF DIAGNOSIS: A PRAGMATIC PERSPECTIVE

\author{
EL DIAGNÓSTICO DEL LENGUAJE Y EL LENGUAJE DEL DIAGNÓSTICO: UNA PERSPECTIVA \\ PRAGMÁTICA
}

\author{
Alexandre Vieira Brito* \\ Luciana Vieira Caliman**
}

\begin{abstract}
RESUMO
A teoria dos atos de fala de John Austin apresenta a linguagem a partir de uma perspectiva pragmática: quando os signos têm um compromisso com a produção de realidades. Seguindo esta direção analítica, neste artigo, articulamos a linguagem-ato e as classificações. Argumenta-se que uma classificação não é mera descrição dos fatos; é produto e produtora de realidades. Dentre as possíveis formas de classificação, abordamos o diagnóstico psiquiátrico como um caso particular na teoria dos atos de fala. Elaboramos um conceito denominado de ato diagnóstico, no qual conjugamos a força da linguagem-ato e do diagnóstico médico a partir de suas implicações políticas no campo social, na produção de sujeitos. Conclui-se que o diagnóstico psiquiátrico produz realidades a partir das mesmas propriedades dos atos de fala. Ao produzir sujeitos, os diagnósticos possuem efeitos existenciais, políticos e sociais que só podem ser analisados no encontro singular entre diagnósticos e sujeitos diagnosticados.
\end{abstract}

Palavras-chave: Linguagem. Pragmática. Diagnóstico psiquiátrico.

\begin{abstract}
Speech Acts, as theorized by John Austin, presents language from a pragmatic perspective. This means that signs/language take on creative forces and produce realities. Through analytical effort, the purpose of this article is to provide the idea that the language-act and classification are related. For further comprehension, we argue that a classification may not be a neutral description about facts. It is substantially the product and the producer of reality. Among many different ways of classification, the psychiatric diagnosis, as a particular case in the theory of Speech Acts, is on which we

\footnotetext{
Texto recebido em 07 de novembro de 2014 e aprovado para publicação em 13 de junho de 2016.

* Psicólogo e Mestre em Psicologia Institucional pela Universidade Federal do Espírito Santo (UFES). E-mail: brito_233@ hotmail.com

** Prof. Adjunta do Departamento de Psicologia da UFES e do Programa de Pós-Graduação em Psicologia Institucional da UFES. E-mail: calimanluciana@gmail.com
} 
will focus. We elaborated a concept - diagnosis act - that combines aspects of the efficacy of the language-act with those of medical diagnosis from its political implications in the social field, when it both come to the production of subjects. In conclusion, a psychiatric diagnosis produces realities from the same properties that speech acts do. Diagnoses produce subjects and so, have existential, political and social effects that can only be analyzed at the particular encounter between diagnoses and diagnosed individuals.

Keywords: Language. Pragmatic. Psychiatric diagnosis.

\section{RESÚMEN}

La teoria de los actos del habla, de John Austin, presenta el lenguaje a partir de una perspectiva pragmática, es decir, cuando los signos tienen un comprometimiento con la producción de realidades. Seguindo esta orientación analítica, en este artículo buscamos crear un eslabón entre el lenguaje - acto y la potencia de las clasificaciones. Arguméntase que uma clasificación no es una descripción sencilla de hechos, es producto y productora de realidades. Dentre las posibles maneras de clasificaciones, planteamos el diagnóstico psiquiátrico mientras un cuadro particular en la teoria de los actos del habla. Elaboramos un concepto llamado de "acto diagnóstico", en lo cual unimos la fuerza del lenguaje-acto y del diagnóstico médico a partir de sus implicaciones políticas en el campo social y en la producción de sujectos. Se puede concluir, por lo tanto, que el diagnóstico psiquiátrico produce realidades a partir de las mismas propiedades de los actos del habla. Cuando se producen sujectos, los diagnósticos poseen efectos existenciales, políticos y sociales que sólo pueden ser analisados en el encuentro singular entre diagnósticos y sujectos diagnosticados .

Palabras clave: Lenguaje. Pragmática. Diagnóstico psiquiátrico.

\section{INTRODUÇÃO}

$\mathrm{N}$ a perspectiva pragmática da linguagem - em particular na teoria dos atos de fala do britânico John Langshaw Austin - um enunciado realiza um ato, ou seja, opera enquanto força criadora de realidades. A partir da pragmática e suas alianças com o mundo, "dizer é fazer". Neste artigo, com o intuito de ampliar nosso pensamento e promover encontros com novas abordagens da linguagem e da questão do enunciado, convocamos Deleuze e Guattari para dialogar com John Austin. Abordaremos a linguagem sem a pretensão de realizar uma espécie de linha do tempo no estudo da pragmática a partir de seus precursores. Também não recorreremos à linguística para a formalização de nosso pensamento; sim,àa pragmática austiniana e do seu diálogo com Deleuze e Guattari que guiaremos 
nosso artigo. É nesta direção que propomos um "diagnóstico da linguagem”. O pensamento de Michel Foucault também se fará presente na análise de alguns limites encontrados na teoria dos atos de fala, pois veremos que - além de existirem condiçôes de eficácia para a realização bem-sucedida do ato - tais condiçôes possuem existência a partir de outros processos necessários para sua existência, neste caso as "condições das condições".

Dentre as formas de uso da linguagem, trataremos do diagnóstico médico psiquiátrico como um caso particular da força do signo na produção de realidades. No que tange à produção de subjetividade, ao exercício da psiquiatria nos tempos atuais é outorgada grande importância. Buscaremos destacar que além de sua existência formal (como em manuais médicos) e informal (como nos ditos populares e no senso-comum) - os diagnósticos produzem efeitos encontrados no interior da linguagem. De forma escrita ou falada, o diagnóstico produz sujeitos pelos seus efeitos (imprevisíveis) de classificação.

Ao classificarmos, não estamos submetidos a uma lei geral da vida que separa as coisas por critérios definidos a priori. A classificação é um aspecto profundamente humano, e seu exercício (separar a vida em espécie, gênero, composição química, classe social ou por caracteres de conduta) não é uma descoberta - como se as coisas estivessem esperando para serem catalogadas mas um processo de produto/produção. É nesta direção que falamos de uma "linguagem do diagnóstico".

Ao realizarmos uma classificação diagnóstica, isso não é sem consequências seja para o sujeito seja para o próprio saber e prática diagnóstica. Em nosso mundo contemporâneo, os diagnósticos estão proliferando no campo médico e social, e os corpos não ficam imunes a esse processo. Como classificação, o diagnóstico assim como o sujeito diagnosticado - também sofre alterações e é reinventado. Uma prova disso é o Manual Diagnóstico e Estatístico de Transtornos Mentais (DSM) que, em sua versão inicial, apresentava 106 categorias; em sua quarta versão, possui 297 desordens mentais. Fato interessante é que o número de classificações não foi reduzido, mas ampliado, transformando-se também - ao longo dos anos - na forma de classificar e nos pressupostos teóricos nos quais estes manuais estão baseados.

Para discutir a questão das classificações - em particular o diagnóstico convocaremos Ian Hacking para fazer relação entre a linguagem-ato (enquanto fonte de produção de mundo) e as classificações como produtoras de sujeitos. Esse autor nos indicará alguns aspectos que compóem a força das classificações, que serão desenvolvidos ao longo de nosso trabalho. 
Ian Hacking também contribuirá no estudo sobre os processos de feedback que as classificaçōes possuem: pois tanto transformam quanto são transformadas. Essa relação entre produto e produção será denominará por ele de "efeito de arco", pois um diagnóstico psiquiátrico vai - de certa forma - interagir tanto consigo, como com os sujeitos, as instituições, com o conhecimento e os especialistas e ser transformado neste processo.

Abordaremos algumas características da medicina psiquiátrica - hoje - e os processos que contribuem para a formação da força médica na atualidade. é possível se ver que tanto a linguagem quanto o diagnóstico e seus efeitos possuem a necessidade de circunstâncias que garantam sua força de produção de realidades e de sujeitos. No caso da psiquiatria, enfocaremos como ela se transformou em um saber privilegiado na descrição e condução de nossas existências. Pensaremos - portanto - o diagnóstico psiquiátrico como possuidor de força de produção de realidades a partir das mesmas propriedades dos atos de fala. Por fim, pretendemos organizar alguns efeitos possíveis do ato de diagnosticar, tendo em vista que são efeitos imprevisíveis, embora sempre dentro de um campo de possibilidades, sendo passível de sofrer as consequências de seu próprio efeito.

\section{A LINGUAGEM E A PRODUÇÃO DE REALIDADES}

A teoria dos atos de fala de Austin (1990) apresenta a linguagem a partir de uma perspectiva pragmática, ou seja, quando os signos possuem força de criação e um compromisso com a produção de realidades e de sujeitos. O que se percebe é que o linguístico e o extralinguístico recebem - a partir da herança austiniana - um novo estatuto e não podem ser pensados isoladamente, pois não se concebe uma separação entre a linguagem e o mundo empírico. Esta concepção teórica pragmática ${ }^{1}$ da linguagem "acusa de insuficiente a definição do signo lingüístico cuja relação com o exterior é exclusivamente de representação. Ao invés de descrever o plano dos fatos, a linguagem, em continuidade com ele, passa também a construí-lo". (Tedesco, 1999, p. 46). Austin (1975), a partir da noção de "falácia descritiva", analisa este acontecimento fundamental:

Supor que 'eu sei' é uma frase descritiva é apenas um exemplo da falácia descritiva, tão comum na filosofia. Mesmo que alguma linguagem seja agora puramente descritiva, a linguagem não era assim na sua origem, e continua não sendo assim em sua maior parte. Proferir óbvias frases 'rituais' nas circunstâncias apropriadas, não é descrever a ação que praticamos, mas praticá-las (p. 110).

Sendo assim, Austin (1990) compõe sua teoria ao pensar os enunciados a partir de três atos realizados por eles: locucionários, ilocucionários e perlocucionários.

1 Este termo tem origem no latim pragmaticus, derivado de uma composição grega a partir de pragma, significando coisa, objeto, e o verbo pracein, que significa fazer, agir. A concepção pragmática da linguagem é o estudo da linguagem enquanto ação, prática social concreta. 
Nessa teoria triádica da linguagem, o primeiro ato é de caráter linguístico, e seus elementos são compostos de acordo com uma determinada língua, formando um enunciado a partir de regras e convençôes. Ele varia de acordo com a língua em questão; segundo Austin (1990), é justamente o ato de dizer algo, sendo de ordem essencialmente linguística.

O segundo é o ato ilocucionário: "o ato propriamente dito, praticado ao se enunciar determinada oração com determinado fim convencional" (Marcondes, 1992, p.15). O ato ilocucionário é a realização do ato na linguagem, e não simplesmente pela linguagem, e "tem uma certa força ao dizer algo" (Austin, 1990, p. 103). Signo e ato formam uma massa comum, identificando-se entre si, pois não fazem referência um ao outro, mas são eles mesmos idênticos.

O ato perlocucionário - por fim - é um ato de outro tipo, distinto dos dois que aqui o precedem. Pode ser compreendido como o efeito ou consequência não convencional de um ato ilocucionário, que não se realiza na linguagem, mas a partir dela tanto em quem fala, quanto em quem ouve. Segundo Austin (1990), o perlocucionário pode fazer - ou não - referência à realização do ato locucionário e ilocucionário, sendo praticado a partir destes com efeitos sobre os sentimentos, pensamentos e ações de quem diz e de quem ouve. Pode haver propósito ou não de tais efeitos, mesmo sem referência direta ao locucionário e ilocucionário.

Com o coroamento do conceito de ilocutório ${ }^{2}$, as enunciações passam a ter implicações pragmáticas e não estariam submetidas a uma norma gramatical. Este destaque para além da estrutura linguística está em acordo com o fato de haver - a partir da teoria de Austin - uma imanência dos enunciados com os atos.

Antes de prosseguirmos, faz-se necessária uma ressalva: na realização de um performativo, não se avaliam enunciados em termos de certo e errado; é preciso destacar que os atos de fala - enquanto prática social - podem não ter sua eficácia garantida. Os performativos obedeceriam a duas condições: de felicidade e de infelicidade (eficácia e ineficácia), "pois o ato de fala é feliz ou não, dependendo das circunstâncias serem ou não adequadas, serem ou não apropriadas" (Lima, 2003, p. 20).

Austin mantém uma espécie de dependência da ordem linguística com as práticas sociais; quando um enunciado opera sua 'realiza-ação', essa vai "além da esfera do linguístico e envolve regras e convençôes sociais e contextuais que estabelecem sua condição de possibilidade" (Marcondes, 1992, p.17). Esses determinantes seriam externos à natureza dos signos, compostos por instituições 
e um conjunto de regras sociais que poderiam garantir que um proferimento performativo fosse bem sucedido ou não (ou, segundo o termo austiniano, feliz ou infeliz).

Vale destacar, neste ponto, as considerações do próprio Austin (1990) acerca de um conjunto de regras aos quais todos proferimentos performativos devem enquadrar-se para que tenham um funcionamento feliz (ou bem sucedido). No caso de transgressão de alguma dessas condiçôes, o ato não tem validade. São elas:

a) (A.1) Deve existir um procedimento convencionalmente aceito que apresente um determinado efeito convencional e que inclua o proferimento de certas palavras, por certas pessoas, e em certas circunstâncias;

b) (A.2) as pessoas e as circunstâncias particulares, em cada caso, devem ser adequadas ao procedimento específico invocado.

c) (B.1) O procedimento tem de ser executado, por todos os participantes, de modo correto e

d) (B.2) completo.

e) (Г.1) Nos casos em que, como ocorre com freqüência, o procedimento visa às pessoas com seus pensamentos e sentimentos, ou visa à instauração de uma conduta correspondente por parte de alguns participantes, então aquele que participa do procedimento, e o invoca deve de fato ter tais pensamentos ou sentimentos, e os participantes devem ter a intenção de se conduzirem de maneira adequada, e, além disso,

f) (Г.2) devem realmente conduzir-se dessa maneira subseqüentemente. (Austin, 1990, p. 31).

Podemos perceber que Austin (1990) divide as regras em três grupos: A. B e $\Gamma$, e não é por acaso que as distingue em letras latinas e gregas, assinalando que o tipo de infelicidade é de natureza distinta. Porém os critérios são dois: desacertos (para A e B) e abusos (para Г).

No caso do desacerto, a violação de suas regras impede a realização do ato performativo, pois as palavras ou as pessoas (e a posição que ocupam) em determinada situação não são adequadas para um ato bem sucedido. A não adequação aos critérios descritos acima conduz a atos malogrados, fracassados: não se trata de proferimentos falsos, mas malogrados. No caso das regras do tipo $\Gamma$, caso sejam transgredidas, não impediriam o ato performativo, mas seriam atos 
vazios, denominados de abusos. Esta perspectiva relaciona-se com as intenções e as insinceridades, pois uma promessa - por exemplo - pode acontecer, mas não ser cumprida.

Vale ressaltar que as condições extralinguísticas por si só de nada servem;, a partir de certas contingências, no entanto, essas convenções podem formar um conjunto eficaz da performatividade da fala. Interessante e mesmo original pensar nas regras de condição dos atos de fala, mas Austin não põe em análise os processos de formação e constituição dessas condições de felicidade. As condições das condições - vamos dizer assim - não são pensadas por ele, e essa seria uma fragilidade na teoria do britânico que abordaremos a seguir.

\section{CONTRIBUIÇÕES PARA ALÉM DA TEORIA DE J. AUSTIN}

Para darmos um passo para além da doutrina das (in)felicidades, é necessário identificar não só as condições já dadas, mas seus processos de constituição. Tedesco (2003) coloca em análise este aspecto do trabalho de Austin e oferecenos indicações de como prosseguir:

É na ligação com os fatos extralinguísticos que a força ilocutória da palavra se esclarece. As condições de felicidade do ato da fala residem nos ritos e convenções existentes na sociedade. Análise insuficiente, diremos, pois neste caso o empírico é identificado a ocorrências factuais. Já há muito estabilizadas nos discursos e outras práticas vigentes. Parte-se de uma situação dada, ou seja, exploram-se condições já estabelecidas, excluindo-se o processo de constituição dessas. É na conjunção entre as teses de Austin e de M. Foucault que encontramos subsídios para o entendimento mais amplo deste processo (Tedesco, 2003, p.2).

Encontramos em Arqueologia do Saber de Foucault (2010) a distinção entre dois tipos de formações de práticas: as discursivas, ou de enunciados; as nãodiscursivas, ou de meios. As formas discursivas seriam - portanto - as de expressão; as não discursivas, de conteúdo nos processos de produção de realidades. É importante - assim - insistir nas formações históricas ${ }^{3}$ e sua determinação a partir daquilo que se vê e do que se diz.

Deleuze (2005) afirma que Foucault concebe a arqueologia como um arquivo audiovisual (p. 73). Isto define uma relação/disjunção entre a linguagem e o extralinguístico, pois esta era uma dificuldade na análise operada por Austin, que alterou de maneira genial a fronteira estabelecida entre o linguístico e o não linguístico com sua pragmática.

3 Passo fundamental para compreendermos a formação das próprias condições de (in)felicidade. 
Sobre este aspecto, Machado (2010) - aluno de Foucault e um dos grandes responsáveis pela transmissão de seu trabalho no Brasil - explica que a Arqueologia do Saber critica - justamente - as formas de interpretação formalizadas (enquanto 'a priori'), pois tudo pode ser dito e visto em diferentes momentos, mas nunca imediata e diretamente, já que o saber de uma época tem suas próprias "condições que tornam os enunciados legíveis e as visibilidades visíveis” (p.166). Nas palavras de Tedesco (1999), a partir "da gênese empírica das formas de conteúdo criamse modos de ver e fazer ver; já da produção das formas de expressão, surgem maneiras específicas de falar, regimes de discursos ou de signos, como preferem Deleuze e Guattari” (p. 73).

Com isso, é possível estabelecer novos rumos ao impasse encontrado nas condições 'a priori' de felicidade/infelicidade da teoria de Austin, na medida em que a produção de realidades está ligada diretamente ao saber.

Nada há antes do saber, porque o saber, segundo o seu novo conceito introduzido por Foucault, define-se por estas combinações de visível e enunciável próprias a cada estrato, a cada formação histórica. O saber é uma disposição prática, um dispositivo de enunciados e de visibilidades (Deleuze, 2005 p. 73).

As linguagens de cada povo, suas práticas, seus lugares, os regimes de cada época têm sua própria maneira de se estabelecer e se congregar, consagrar, transformar. Dependem das combinações/relações audiovisuais que se produzem, do que se faz ver (conteúdo) e do que se diz (expressão), ambos essenciais para pensarmos na linguagem como força produtora de realidades.

No entanto, estas relações também produzem constantes, embora sempre provisórias. "Não são apenas as variáveis linguísticas de expressão, mas também as variáveis não-linguísticas de conteúdo, que entram respectivamente em relações de oposição ou distinções formais, capazes de liberar constantes" (Deleuze \& Guattari, 2008, p. 55). E estas constantes também seriam importantes na formação das condições de felicidade - de certa forma, essas constantes seriam as condições formalizadas - que dão força a um ato ilocucionário, apesar de alguns autores considerarem as constantes enquanto 'a priori', sem se preocupar com suas formaçôes.

Em acordo com a teoria dos enunciados em Foucault (2010), "não se poderia estabelecer uma relação biunívoca entre o conjunto dos enunciados e dos atos ilocutórios" (p. 94), pois são necessários mais de um enunciado para se efetuar um ato de fala. 
Além disso, certos atos ilocutórios só podem ser considerados como acabados em sua unidade singular se vários enunciados tiverem sido articulados, cada um no lugar que the convém. Esses atos são, pois, constituídos pela série ou soma desses enunciados, por sua necessária justaposição (Foucault, 2010, p. 94).

O enunciado seria, portanto, uma multiplicidade e é anterior às frases e proposiçôes, além de ser ele quem define o ato ilocutório, distanciando-se de uma teoria linguística.

Um quadro classificatório das espécies botânicas é constituído de enunciados, não de frases (Genera plantarum de Lineu é um livro inteiramente constituído de enunciados, em que não podemos reconhecer mais que um número restrito de frases); uma árvore genealógica, um livro contábil, as estimativas de um balanço comercial, são enunciados: onde estão as frases? (Foucault, 2010, p. 93).

Deleuze e Guattari (2008) remetem os enunciados aos agenciamentos marcados pela multiplicidade coletiva e híbrida - na qual o próprio agenciamento seria condição da linguagem que - assim - estaria para além de um isolamento no campo do linguístico ou de representação de mundo.

Partindo, portanto, da abordagem pragmática da linguagem que - como vimos - ressalta o caráter produtor e criador da mesma, voltamos nosso olhar para uma forma específica de linguagem: as classificaçôes de pessoas. Interessa pensar o papel das classificações no jogo complexo de criação e produção dos sujeitos por elas nomeados. Dentre as classificações de pessoas, analisamos o papel fundamental das classificações diagnósticas psiquiátricas na constituição das subjetividades contemporâneas. Para discutir este aspecto, nosso intercessor será Hacking (2009), filósofo canadense responsável pelas ideias das quais nos valemos para produzir o encontro da pragmática da linguagem com os modos de classificar pessoas.

\section{HACKING, AS CLASSIFICAÇÕES E O DIAGNÓSTICO}

Caponi e Brzozowski (2009) apontam que Ian Hacking "diz que nosso mundo é um mundo de classificações e que essas classificações, ou nomes, têm efeitos particulares quando se referem a comportamentos de pessoas" (p. 1166). Nesses casos, as classificações portam uma força política, produzem transformações que soam por meio da linguagem, com potência de personificação e despersonificação - dois processos aliados ${ }^{4}$.

4 Persona têm justamente sua origem em per + sonare, que significa "soar através de". No ato de fala, em particular, teríamos uma força "através do som", e assim pensamos a confluência entre diagnose e semiose. A essa confluência daremos o nome de ato diagnóstico, sendo ele, portanto, um ato misto. 
Assim - seguindo Hacking (2009) - consideramos o diagnóstico uma forma de classificação: uma classifica-ação, uma ação de classificar e ao classificar. A união que propomos realizar entre diagnose e semiose é contemplada de maneira privilegiada nesse aspecto. Em ambos os termos, há uma relação direta com a noção de ação;no caso da semiose, opera-se uma ação do signo; na diagnose, teríamos uma ação do conhecimento.

Hacking (2009) contempla a relação entre o conhecimento e as classificações, apresentando a relevância de articulá-los. Em entrevista a Regner (2000), afirma: "Penso que seja importante porque nosso conhecimento das pessoas, frequentemente expresso em nossas classificaçóes, tem um enorme efeito sobre nós, e isso pode apenas aumentar no próximo século" (p. 10).

A análise de Hacking (2009) sobre o efeito das classificações na produção ou invenção de pessoas (making up people) introduz uma interessante questão. A classificação pode produzir efeitos e esses não são aleatórios, apesar de serem imprevisíveis. $\mathrm{O}$ interessante é que o efeito pode se dar na própria classificação, criando - assim - novas categorias, extinguindo antigas, unindo diversas numa só, etc.

No que tange aos nossos interesses neste artigo, voltamo-nos para o aspecto de reciprocidade ou de coemergência entre classificação e tipo classificado. Para o autor, "categorias de pessoas passam a existir na mesma hora em que tipos de pessoas passam a existir de modo a se encaixarem nessas categorias, e há uma interação de mão dupla entre esses processos" (Hacking, 2009, p.63). Em um capítulo traduzido como Inventando Pessoas, Hacking nos diz que "a categoria e as pessoas inseridas nela emergiram juntas” (Hacking, 2009, p.123). Classificação e sujeito classificado surgem - concomitantemente - resultantes de uma ação recíproca em que ambos são ativos. Ação que permanece na medida em que - mesmo após a constituição da classificação e do sujeito classificado - esses continuam interagindo e interferindo mutuamente.

A relação estabelecida entre a classificação e os sujeitos classificados é apresentada de forma precisa e condensada por Brzozowski e Caponi (2009) a partir de um conceito de Hacking que tem a função de articulá-los: a noção de efeito de arco.

[...] indivíduos classificados interagem com sua classificação, e esta pode se modificar em razão dessa interação. Isso configura o que Hacking chama de efeito de arco. O efeito de arco é, na verdade, um ciclo entre os indivíduos que são considerados membros da classe e a própria classe (p. 1172).

Hacking (2009) também afirma que só é possível ser uma pessoa, um tipo de pessoa, "em determinada época, em um determinado lugar, em determinado 
ambiente social” (p. 126). São necessárias situações sócio-históricas e certas circunstâncias para que os sujeitos passem a existir ou deixem de existir. Esses cenários são, segundo o autor, "essencialmente históricos", e "trazem à vida novas categorias que, em parte, trazem à vida novos tipos de pessoas" (p. 64). Tratase da força ilocucionária da classificação, sendo essa um ato de produção de realidades, de sujeitos e de novos discursos e práticas.

Entendemos, assim, o diagnóstico como uma forma de classificação, para a qual

[...] existem características definidas, e na qual alguns indivíduos com essas características se enquadram. Mas para que um diagnóstico, uma classificação, seja levada em consideração, entre na sociedade, é necessário que haja algo que a legitime, precisa haver uma instituição que a torne verdadeira, que a utilize (Brzozowski \& Caponi, 2009, p.1178).

O efeito do diagnóstico se dá - sobretudo - no corpo. Escreve-se sobre o corpo, destacam-se atribuições e atribui-se um diagnóstico ao corpo, mesmo quando se trata de um diagnóstico "mental". Os marcadores da doença podem ser biológicos, corporificados e localizados no corpo, no organismo do paciente ou não. Sua etiologia pode não ser necessariamente da ordem biomédica, como acontece na maioria dos casos dos chamados "transtornos mentais". Assim, independentemente de ter na sua base o argumento da existência de uma causa orgânica, o ato diagnóstico é uma potência que imprime um atributo aos corpos - no âmbito da expressão - provocando uma transformação corporal a partir das forças do incorpóreo (da linguagem).

Neste sentido, distanciamo-nos da noção de acordo com a qual o diagnóstico resulta de uma descrição de atributos encontrados no corpo do sujeito como um decalque, como se a natureza oferecesse à linguagem uma verdade em forma de diagnóstico. Um diagnóstico opera criando corpos, posições sociais, discursos, enunciados, formas de cuidado e sofrimento, direitos e deveres, manejos burocráticos, etc. Em síntese, o que conceituamos enquanto ato diagnóstico (semiose + diagnose) é uma ação que se efetiva em um ato de fala a partir de um diagnóstico - formalizado ou não - podendo ou não ter eficácia (no que tange à impressão de um atributo ou sentido a um corpo, a uma vida). O diagnóstico não é apenas uma nomeação ou descrição. Como ato de fala, como linguagem, o ato diagnóstico é uma força que pode transformar e ser transformada, impulsionada por uma de suas gêneses: $o$ ato ilocucionário.

É importante ainda ressaltar que - no que tange aos efeitos dos diagnósticos (principalmente quando se trata de "diagnósticos mentais") - desviamo-nos da 
formulação de uma teoria do rótulo ou estigma, para pensarmos nos possíveis, e imprevisíveis, efeitos do diagnóstico. Assim, estamos de acordo com Deleuze e Guattari quando afirmam que "Um tipo de enunciado só pode ser avaliado em função de suas implicações pragmáticas, isto é, de sua relação com pressupostos implícitos, com atos imanentes ou transformaçoes incorpóreas que ela exprime, e que vão introduzir novos recortes entre os corpos." (Deleuze \& Guattari, 2008, p. 23).

Por um lado, um certo "desejo de diagnóstico" é impulsionado pelo efeito de legitimação de um sofrimento ou problema que, sem o diagnóstico, é destituído de realidade. Por outro, há situações nas quais o efeito do diagnóstico impulsiona um processo de tentativa de destituição de sentido do próprio diagnóstico: efeito de arco. Ortega (2009) demonstra claramente como - no caso do autismo - a apropriação por familiares e paciente das explicações neurológicas sobre a etiologia do transtorno tem levado a um movimento de despatologização do autismo e uma luta pela defesa do argumento da neurodiversidade. A explicação neurológica para a "vida autista" é reforçada ao mesmo tempo em que se luta pela despatologização ou deslegitimação do diagnóstico de autismo.

Neste movimento, um autista pode deixar de ser considerado um sujeito com inabilidade social e resistir a um tratamento que visa a uma ortopedia comportamental e se tornar alguém com uma forma singular de ver o mundo, até mesmo desenvolver uma criatividade que supera aquilo que a categorização formal poderia lhe causar. Afinal, o diagnóstico não é bom ou mau a priori (nem pretendemos analisá-lo moralmente), mas tornou-se uma das classificações humanas mais complexas e comuns em nossa atualidade, sendo parte de nossa sociedade. Neste sentido, importa ressaltar que a classificação diagnóstica principalmente psiquiátrica - produz realidades, produz sujeitos.

No entanto, na contemporaneidade, vimos ser fortalecida uma racionalidade biomédica que obscurece o efeito performativo do diagnóstico na medida em que descreve sua prática diagnóstica como objetiva, neutra e tanto mais real quanto menos interferida pelos condicionantes históricos. Para a racionalidade biomédica atual, diagnosticar é revelar, desvendar algo que se encontra no sujeito, embora passível de ser descoberto sem a narrativa do mesmo. Nela, "o paciente só será fonte fidedigna de informação quando for completamente despersonalizado" (Camargo Júnior, 2005, p.216).

E esta é somente uma crença pontual no âmbito mais geral de uma cultura marcada pela ênfase no corpo, ou melhor, no cérebro, como sendo a sede da alma, da identidade, da política, da religião, do sentimento moral, do sofrimento mental. Para a biopsiquiatria hoje em voga, um sofrimento só é sofrimento, uma doença só é doença, um diagnóstico só é um diagnóstico quando este for um biodiagnóstico; tudo o mais é apenas psicológico ou social e, portanto, menos real. Uma patologia só é realmente real quando sua existência biológica é comprovada (Caliman, 2011, p.113). 
É nesta cena histórica que precisamos situar a prática diagnóstica atual quando analisamos seus efeitos; sem desconsiderar, no entanto, que sua apropriação é sempre singular e situada e que seus efeitos não podem ser definidos a priori, anterior à experiência de ser diagnosticado.

\section{OS EFEITOS DIAGNÓSTICOS}

Como vimos, o ato diagnóstico é o diagnóstico com força pragmática: a união do ato ilocucionário com a ideia geral de diagnóstico (semiose + diagnose). $\mathrm{O}$ ato diagnóstico consiste na produção de realidades (efeitos/sujeitos); caso esses não compareçam - cedo ou tarde - não consideraremos que foi realizado um ato feliz. Neste artigo, analisamos as classificaçôes psiquiátricas como biodiagnósticos definidos pela busca (ou postulação) de causas biológicas e sinais externos que possam circunscrever o quadro patológico. Diagnósticos "mentais" que sofrem uma redução radical de sua complexidade ao critério anatomofisiológico ou neuroquímico e que exercem efeitos de produção de realidade, de produção de sujeitos.

No âmbito da linguagem, a própria natureza do ato diagnóstico aponta para suas consequências como sendo da ordem do perlocucionário. Diferente do ato ilocucionário, em que o ato se realiza na linguagem, o perlocucionário se realiza a partir dela, com efeitos - e essa é a questão - não convencionais. Ou seja, os efeitos operados por meio da linguagem-ato não são estabelecidos a priori, ultrapassando os domínios da ação realizada ou mesmo as intenções. Afinal, é possível que determinadas práticas ou determinados ditos sejam postulados com determinadas intenções (conscientes ou não). No entanto, não há garantias de que elas sejam plenamente satisfeitas; por vezes, seu oposto se realiza.

$\mathrm{Na}$ atualidade, no que diz respeito à psiquiatria - apesar de não ser algo exclusivo ou restrito a esse saber - o efeito produtor de sujeitos parece ser ainda mais evidente, embora a própria psiquiatria afirme o contrário, ao postular o efeito "revelador" e neutro do diagnóstico. Diferentemente, vemos que o diagnóstico produz efeitos existenciais, sociais e políticos cada vez mais evidentes. No que tange ao efeito existencial, o diagnóstico pode surgir como um sobrenome, ou mesmo como uma forma de identificação de um sujeito ${ }^{5}$. Por vezes, o sujeito diagnosticado tende a responder à questão "quem sou eu" revelando seu diagnóstico, fortalecendo o que Ortega (2003) define por bioidentidades. O sujeito se localiza e se orienta, identifica-se (e é identificado), reconhece-se (e é reconhecido) por meio de um biodiagnóstico. Enquanto uma conduta, angústia e/ou o sofrimento podem desorganizar, a classificação diagnóstica produzir "certa

5 Como se referir ao sujeito pelo seu número de internação, ou pelo código de seu CID/DSM, ou pelo seu sintoma, assim como acontece com sujeitos reconhecidos no sistema socioeducativo ou penitenciário apenas pelo seu ato infracional ou crime. 
organização". Isso influencia as diversas formas como o sujeito se percebe e se comporta, atuando também na constituição de novas biossociabilidades.

$\mathrm{Na}$ esfera política, a partir de Caliman (2011), podemos afirmar que ter um biodiagnóstico pode, por exemplo, transformar a pessoa diagnostica num sujeito de direitos. Há - por exemplo - todo um sistema de direitos e deveres entre doentes e sociedade, no qual sujeitos diagnosticados reúnem-se e agrupam-se a partir de uma bioidentidade comum, nesse caso, de sua classificação psiquiátrica.

Esses grupos de apoio certamente não são novidades - os primeiros movimentos remontam ao fim da primeira guerra Mundial. O que há de novo no seu desenvolvimento na contemporaneidade é o fato de os próprios pacientes e cuidadores manejarem um conhecimento altamente especializado sobre sua condição, criando novas formas de ativismos político na saúde (Ortega \& Zorzanelli, 2010, p.161).

Percebe-se que há - nestes casos -não apenas o efeito de rotulação e medicalização potencialmente presente no diagnóstico, mas um "ganho" existencial e político diante das classificações ao transformar identidades, até então desagrupadas e sem legitimidade, em entidades política e socialmente reconhecidas.

Alguns dos atos diagnósticos também podem comportar efeitos de desculpabilização do sujeito no que tange a seu comportamento, descrito agora como sintoma de uma doença situada no corpo, no cérebro. Algumas pessoas preferem ser "chamadas de doentes mentais do que de preguiçosas ou desorganizadas" (Brzozowski et al., 2010, p.902). Em certa medida, o diagnóstico biomédico cumpre o efeito de nos aliviar do fardo moral imbuído no brado da responsabilidade individual e da lógica da escolha (Mol, 2008).

O efeito desculpabilizador dos diagnósticos reverbera não apenas nos sujeitos classificados, como também nos médicos. Na lógica biomédica atual, a ausência de um diagnóstico claro e concluso leva - muitas vezes - a uma desqualificação do profissional médico, visto como ineficiente. $\mathrm{O}$ diagnóstico, mesmo quando acompanhado de um prognóstico desfavorável, apazigua este julgamento.

Um biodiagnóstico cumpre-porvezes - a função de simplificar e individualizar uma complexa demanda de ajuda que chega aos consultórios médicos. E isso produz também outros efeitos, pois "ao biologizar questôes sociais, todo sistema social se transforma isento de responsabilidades" (Brzozowski et al., 2010, p.900). Para as autoras, esse efeito desloca ou reduz a análise das possíveis causas do problema que é, por meio do diagnóstico, individualizado e biologizado. Ao biologizar a não-aprendizagem, por exemplo, não é colocada em questão 
as formas de aprendizagem, as escolas atuais, a infância, a família, as formas de governo, etc.

Vale ressaltar - no entanto - que o ato diagnóstico nem sempre é "feliz". $\mathrm{Na}$ medida em que o limite entre saúde e doença tornou-se muito tênue e impreciso, diagnósticos podem também ser recusados.

As motivações que levam à desmedicalização ou recusa do diagnóstico por parte de seus portadores são muitas e complexas. Uma questão crucial implicada nesta reflexão é a de que a "saúde" - e, portanto, também a "doença" - é culturalmente configurada e socialmente sustentada, isto é, possui diversos significados culturais, e diferentes ideologias estão envolvidas em sua definição (Gaudenzi \& Ortega, 2012, p. 10).

Em efeito arco, criam-se (ou não) novos sujeitos e grupos, novas previsões, medicações, estatísticas, prognósticos, mercados, instituições, políticas públicas, novos procedimentos especializados, segregações e agregações, esperanças e desilusões, resignação e invenção. Acerca dos efeitos dos biodiagnósticos na atualidade, Caliman (2011) conclui que seu impacto "não é óbvio e não pode ser definido a priori, ele precisa ser interrogado, narrado pelos sujeitos que vivem cotidianamente a experiência de ser diagnosticado ou de cuidar de alguém diagnosticado" (p. 114).

\section{CONSIDERAÇŌES FINAIS}

Neste artigo, buscamos unir dois elementos distintos: a linguagem-ato e o diagnóstico. Demos um passo na possibilidade de unir o uso da medicina psiquiátrica - e um de seus produtos, o diagnóstico - com a função dos signos, e podemos perceber que o diagnóstico possui a mesma potência encontrada na linguagem-ato. Além disso, ambos têm a necessidade de condições que lhe ofereçam força de existência e de um uso eficaz. Concluímos que o diagnóstico encontrado na ciência psiquiátrica pode ser considerado e estudado enquanto um dos casos possíveis no âmbito da pragmática da linguagem.

Também avançamos ao convocar as ideias de Ian Hacking para vincular o enunciado como ato produtor de realidades com a noção de diagnóstico como classificação: uma das formas de classificações mais importantes em nossa época multiplicando-se cada vez mais nos manuais de doença mental ao longo dos anos.

As nomenclaturas psiquiátricas estão pulverizadas no corpo social de tal modo que qualquer sujeito é capaz de se apropriar de uma classificação, denominarse e reconhecer-se como tal. Enquanto um fenômeno que encontra forças nas 
instituições, convençôes, na ciência, em práticas e na linguagem, o diagnóstico tem características encontradas no âmbito da própria linguagem. A partir dessas forças, as nomeações também têm poder de convencimento social, em que a biomedicina funciona como sistema simbólico privilegiado para produzir explicações sobre tudo: produz coerência, validação, manejo burocrático, assistência legal e legitimidade para as condições de sofrimento físico e mental. Uma condição - na medida em que é vista como patológica, merecedora de cuidado psiquiátrico - abre possibilidade de legitimidade social e mesmo legal aos indivíduos por ela acometidos. Um diagnóstico pode ser o motor na mudança da percepção dos sujeitos, mudando as formas do sujeito perceber a si e ao mundo, criando identidade, produzindo novas relaçóes com o corpo e com o outro.

Um ato diagnóstico pode modificar um passado (por retroação), abrir novas possibilidades, bem como fechá-las; pode transformar e destacar certos aspectos - sempre de forma instantânea e em constante interação. Afinal, com os enunciados, não nos referimos ao sujeito e às realidades, mas intervimos, de algum modo, produzimos atribuições contínuas aos corpos.

Em sintonia com os estudos da pragmática da linguagem, defendemos a ideia que uma classificação diagnóstica não é mera descrição neutra acerca dos fatos, ou que o mundo (a patologia, por exemplo) estava apenas à espera de ser descoberto e classificado, mas que uma síndrome do pânico, por exemplo, para existir como tal passa por um processo de constituição que nunca cessa, mesmo quando aparentemente cristalizado em um manual de doenças. As classificações psiquiátricas - ao incidirem sobre a vida dos sujeitos - interferem em seus corpos, alteram e produzem novos sujeitos, são transformadas ao longo do tempo, sendo parte de um processo institucional, econômico, social.

Quais os tipos de pessoas e quais realidades a prática diagnóstica produz é uma interrogação que precisa ser mantida em aberto, alimentando as análises sobre os efeitos dos diagnósticos nas pessoas diagnosticadas e suas instituições de pertencimento, bem como afirmando a prática diagnóstica como um exercício performativo. Falamos aqui de efeitos que são imprevisíveis, que se formam e reformam na interação entre classificação e sujeito classificado. Ao mesmo tempo, as classificaçõos (diagnósticas) estão em interação constante com os "tipos de pessoas" sobre os quais elas incidem, sendo também por eles apropriadas e transformadas. 


\section{REFERÊNCIAS}

Austin, J. L. (1975). Outras mentes. (Vol. 52). São Paulo: Abril Cultural. (Coleção os Pensadores)

Austin, J. L. (1990). Quando dizer é fazer: palavras e ação. In D. M. Souza Filho (Trad.) Porto Alegre: Artes Médicas.

Brzozowski, F. S., Brzozowski, J., \& Caponi, S. (2010). Classificações Interativas: o caso do Transtorno de Déficit de atenção com Hiperatividade infantil. Interface - Comunicação, Saúde e Educação, 14 (35), p. 891-904.

Brozozowsky, F. S., \& Caponi, S. (2009). Transtorno de déficit de atenção com hiperatividade: classificação e classificados. Physis, 19 (4), 1165-1187.

Caliman, L. V. (2011). Os bio diagnósticos na era das cidadanias biológicas. In Anais, 2 Simpósio: Cidadania biologizada e judicializada: a produção do sofrimento psíquico.

Camargo Júnior, K. R. (2005). A Biomedicina. Physis. Revista de Saúde Coletiva, Rio de Janeiro, 15 (supl.), 177-201.

Deleuze, G. (2005). Foucault. Lisboa: Edições 70.

Deleuze, G., \& Guattari, F. (2008) Mil platôs: capitalismo e esquizofrenia. (Vol. 2) (5a ed.) São Paulo: Editora 34.

Foucault, M. (2010). A arqueologia do saber. (7a ed.). Rio de Janeiro: Forense Universitária.

Gaudenzi, P., \& Ortega, F. (2012). O estatuto da medicalização e as interpretações de Ivan Illich e Michel Foucault como ferramentas conceituais para o estudo da desmedicalização. Interface - Comunicação, Saúde, Educação, 16(40).

Hacking, I. (2009) Ontologia histórica. São Paulo: Editora Unisinos.

Lima, R. R. G. (2003). Comunicação como ação: desdobramentos do performativo desde Austin. (Dissertação de Mestrado). Pontifícia Universidade Católica de São Paulo, São Paulo.

Machado, R. (2010). Deleuze, a arte e a filosofia. (2a ed.). Rio de janeiro: Jorge Zahar.

Marcondes, D. (1992). Filosofia, linguagem e comunicação. (2a ed.) São Paulo: Cortez. 
Mol, A. (2008). The Logic of Care - Health and the Problem of Patient Choice. London and New York: Routledge.

Ortega, F. (2003) Práticas de ascese corporal e constituição de bioidentidades. Cadernos Saúde Coletiva, 11(1), 59-77.

Ortega, F. (2009). Deficiência, autismo e neurodiversidade. Ciência \& Saúde Coletiva, Rio de janeiro, 14(1), 67-77.

Ortega, F., \& Zorzanelli, R. (2010). O corpo em evidência: a ciência e a redefinição do humano. Rio de Janeiro: Civilização Brasileira.

Tedesco, S. H. (2003). A natureza coletiva do elo linguagem-subjetividade. Psicologia: Teoria e Pesquisa, Brasília, 19(1), 85-89.

Tedesco, S. H. (1999). Estilo e subjetividade: consideraçôes a partir do estudo da linguagem. (Doutorado em Psicologia). Pontifícia Universidade Católica de São Paulo, São Paulo. 